\title{
Systemic Analysis on Risk Factors for Breast Cancer Related Lymphedema
}

\author{
Ya-Qun Zhu, Yu-Huan Xie, Feng-Huan Liu, Qi Guo, Pei-Pei Shen, Ye Tian*
}

\begin{abstract}
Background: To evaluate risk factors for upper extremity lymphedema due to breast cancer surgery. Materials and Methods: Clinical studies published on PubMed, Ovid, EMbase, and Cochrane Library from January 1996 to December 2012 were selected. Results: Twenty-five studies were identified, including 12,104 patients. Six risk factors related to the incidence of lymphedema after breast cancer treatment were detected: axillary lymph node dissection $(\mathrm{OR}=3.73,95 \% \mathrm{CI} 1.16$ to 11.96$)$, postoperative complications $(\mathrm{OR}=2.64,95 \% \mathrm{CI} 1.10$ to 6.30), hypertension (OR=1.83, 95\% CI 1.38 to 2.42 ), high body mass index (OR=1.80, 95\% CI 1.30 to 2.49), chemotherapy $(\mathrm{OR}=1.38,95 \% \mathrm{CI} 1.07$ to 1.79$)$ and radiotherapy $(\mathrm{OR}=1.35,95 \% \mathrm{CI} 1.10$ to 1.66). We found significant protective factors for lymphedema: pathologic $\mathrm{T}$ classification $(\mathrm{OR}=0.57,95 \% \mathrm{CI} 0.36$ to 0.91$)$ and stage $(\mathrm{OR}=0.60,95 \% \mathrm{CI} 0.39$ to 0.93$)$, while some factors, like age, number of positive lymph nodes, number of lymph node dissection, demonstrated no obvious correlation. Conclusions: Axillary lymph node dissection, postoperative complications, hypertension, body mass index, chemotherapy, radiotherapy are risk factors for lymphedema after breast cancer treatment. Attention should be paid to patients with risk factors to prevent the occurrence of lymphedema.
\end{abstract}

Keywords: Breast cancer - upper extremity surgery - lymphedema - risk factors

Asian Pac J Cancer Prev, 15 (16), 6535-6541

\section{Introduction}

Breast cancer related lymphedema (BCRL)is a chronic and common complication caused by abnormal accumulation of protein-rich fluid in the interstitial space secondary to inadequate lymphatic drainage, which manifests unilateral or bilateral upper extremity swelling in the clinical. (Cheville et al., 2003). Lymphedema and its related symptoms (pain, heaviness, tightness, and decreased range of motion) seriously affect recreational and social relationships (Hayes et al., 2012). Patients with BCRL have a lower quality of life, a higher level of anxiety or depression (Pyszel et al., 2006; Heiney et al., 2007).

Due to differences in study designs, measurement methods and criterias, length of follow-up, lymphedema definitions and timing of lymphedema measurement since diagnosis and treatment, previous studies have shown about $20 \%$ of breast cancer survivors will develop lymphedema. (sakorafas et al., 2006) In recent years, many studies have established risk factors of BCRL, but conclusions are not consistent, which even contradict each other from some studies. The study systematically reviews the risk factors for BCRL with meta-analysis method to increase the credibility of the conclusions for the purpose of providing scientific evidence for early prevention of lymphedema in clinical work.

\section{Materials and Methods}

\section{Literature Search}

We searched comprehensively clinical studies which were published in PubMed, Ovid, EMbase, the Cochrane Library from January 1, 1996 to December 30, 2012. The MeSH headings and keywords in this search used included "breast cancer", "upper extremity", "lymphedema" and "risk factors" Relevant articles were identified and their references were checked for additional studies. The search strategy used: ( ("Breast Neoplasms” (Mesh) AND “Upper Extremity" (Mesh)) AND ("Lymphedema" (Mesh) OR "Edema" (Mesh)) AND ("1996/01/01" (PDAT) : "2012/12/31" (PDAT))

\section{Inclusion and Exclusion Criteria}

Inclusion criteria: studies of female patients with unilateral breast cancer; the primary studies of risk factors for BCRL published abroad.

Exclusion criteria: studies of patients with bilateral breast cancer, primary lymphoedema, or metastatic disease $(\mathrm{n}=258)$; review, meta-analyses, editorial, comment , and case reports $(n=121)$; studies that did not either inform OR and $95 \% \mathrm{CI}$ or provide adequate information to calculate the OR and its variance $(n=39)$; non-English-language studies $(n=8)$. 


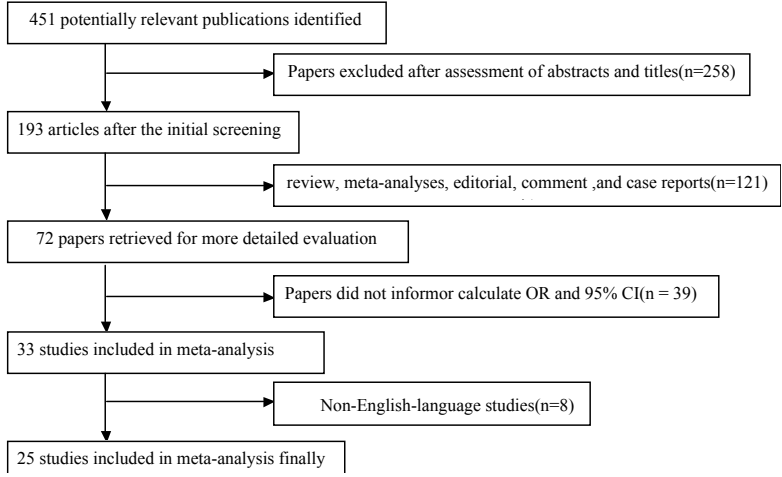

Figure 1. Flow Diagram of Study Assessment and Inclusion in the Meta-Analysis

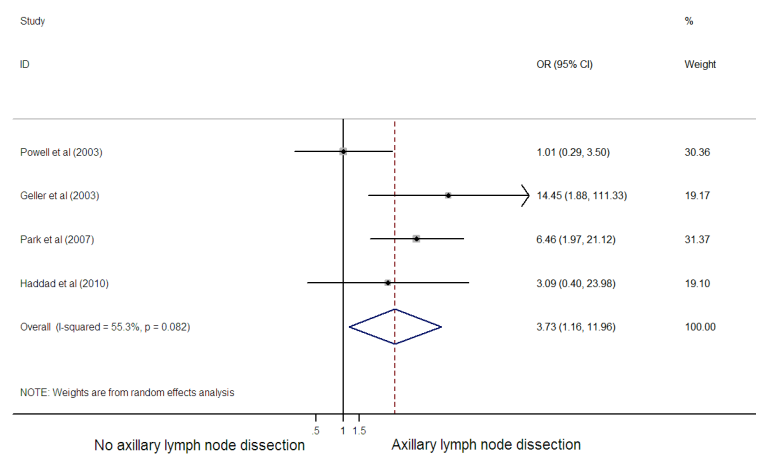

Figure 2. Forest Plot of Axillary Lymph Node Dissection

\section{Quality evaluation}

Two authors assessed the quality of the included studies independently with NOS (Neweastle. Ottawa Scale) iterns by Egger et al. (6) Evaluation indicators include selection , comparability and outcome in cohort study. A study can be awarded a maximum of one star for each numbered item within the Selection and Outcome categories. A maximum of two stars can be given for Comparability. Quality of study is divided into A (eight and more stars) and B (seven stars).

\section{Data Abstraction}

Two authors selected articles independently with disagreements resolved through discussion with a third author to attain consensus according to predetermined inclusion and exclusion criteria. They extracted data for author, year, study location (country), sample size, method of lymphedema measurement, definition of lymphedema, incidence or prevalence of lymphedema, and risk factors. Lymphedema measurement refers to the technique used to determine the presence of lymphedema and included: arm circumference (centimeters), water displacement (volume), multiple-frequency bioelectrical impedance analysis (MFBIA), clinician diagnosis, self-report and unclear.

\section{Statistical analysis}

Establish a database using Excel 2007 software and run preliminary calculation Statistical analysis was done by Stata 10.0 and RevMan 5.2 software. (Cheville et al., 2003) Test heterogeneity of studies using Q test: $p<0.05$ was considered statistically heterogeneity. Choose a fixed

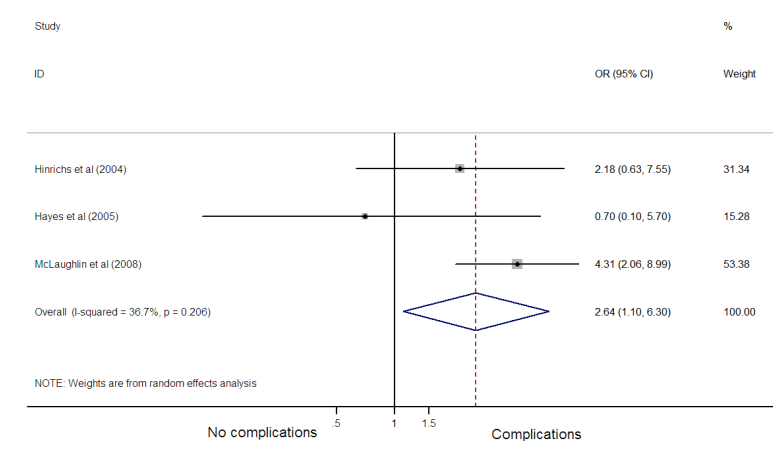

Figure 3. Forest Plot of Postoperative Complications

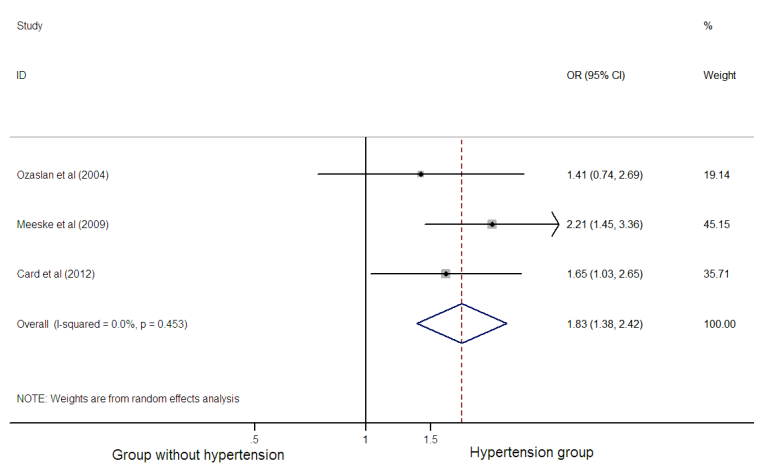

Figure 4. Forest Plot of Hypertension

or random effects model to estimate the pooled OR and 95\% CI for these dichotomous factors according to the test results of heterogeneity. If there was heterogeneity between studies, we will use a random effect model (DerSimonian. Laird). If no, use a fixed effect model (Mantel.Haenszel). Subgroup analysis investigate sources of heterogeneity when necessary. (Hayes et al., 2012) Measure the degree of heterogeneity between studies using I-squared test. We can accept heterogeneity when $\mathrm{I}^{2} \leq 50 \%$ in the Cochrane systematic review. Assess the existence of publication bias using Egger's test (Egger et al., 1997).

\section{Results}

We identified 451 potentially relevant citations, but 25papers (8-32) were included in our analysis after a series of assessment (Figure 1). 12 studies were from America, 4 studies were from Australia and others from Germany, Italy, Korea, India and so on. Nearly half of studies measured lymphedema based on differences in arm circumference.

Of the 25 studies, 18 studies were eight stars (A) and 7 studies were seven stars (B). The quality of included studies was higher. General characteristics of studies included and study quality in the meta-analysis were as followings: (Table 1). We assessed the presence of publication bias using Egger's test. Nineteen were not statistically significant in publication bias $(p>0.05)$ from 21 relevant risks (Table2). The publication bias of this study is small, so the combined results of the research were reliable basically.

In view of inconsistency between $t$ the incidences and risk factors of BCRL among studies, that is there was heterogeneity between studies, we use a random effects model to estimate and analyze various risk factors. We stratified data by different measurement methods and 
DOI:http://dx.doi.org/10.7314/APJCP.2014.15.16.6535

Systemic Analysis on Risk Factors for Breast Cancer Related Lymphedema

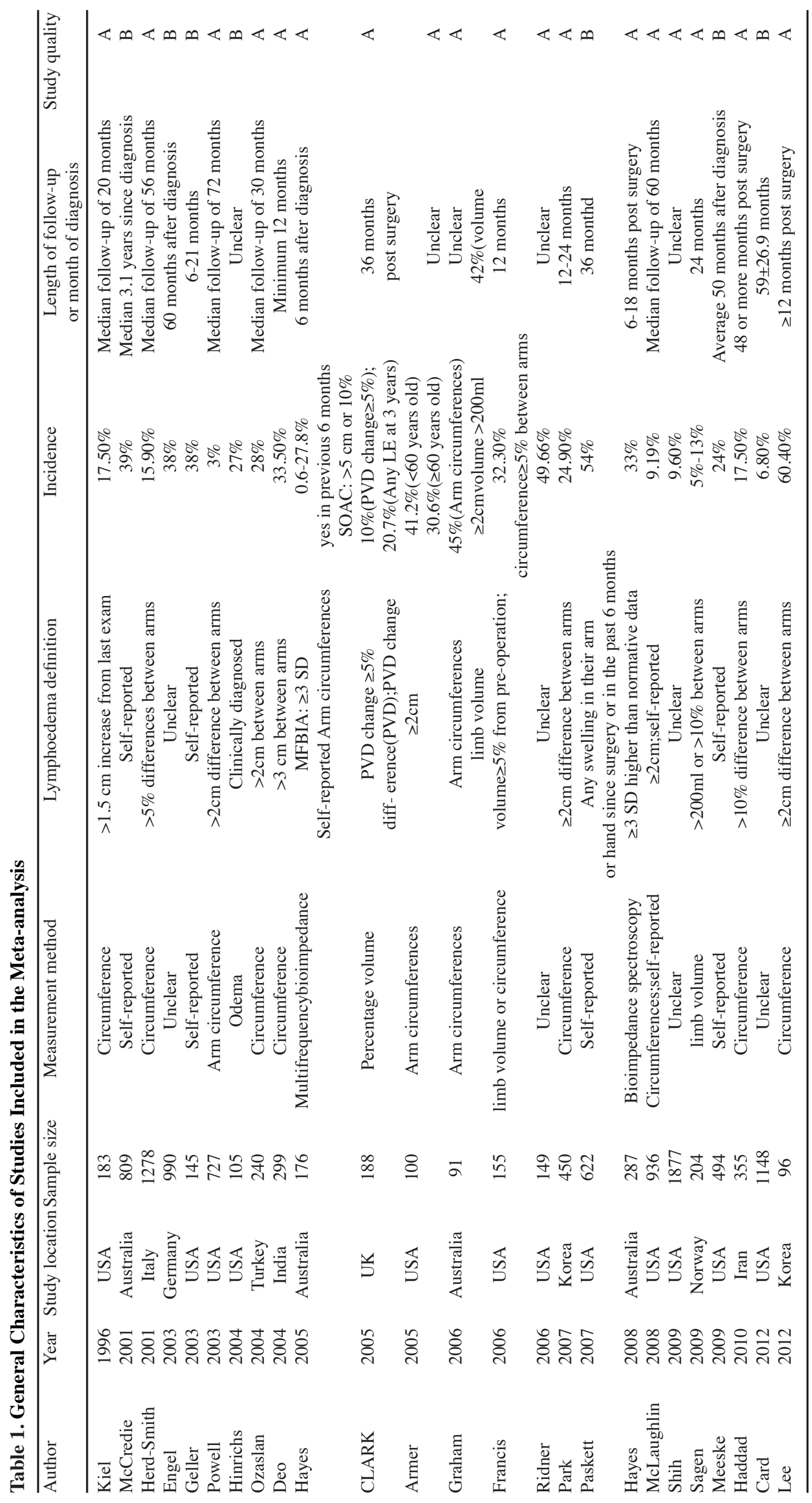


Table 2. Results of Meta-analysis and Egger's Test and Heterogeneity

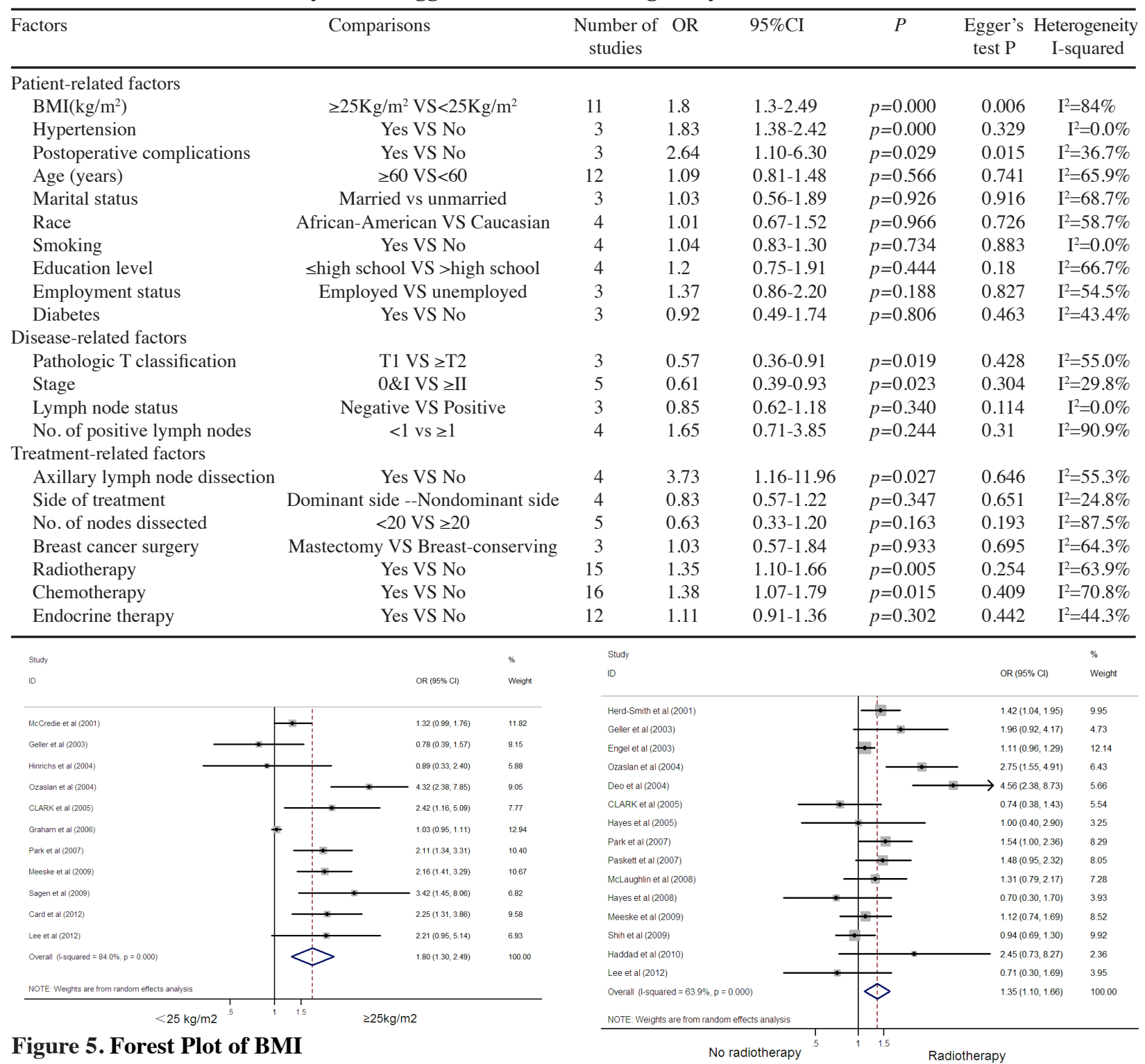

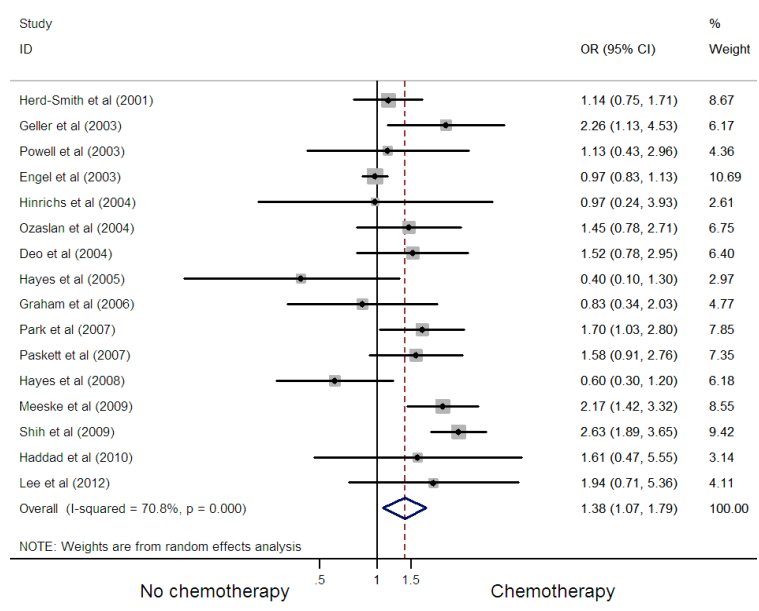

\section{Figure 6. Forest Plot of Chemotherapy}

locations of lymphedema in purpose of identifying and decreasing heterogeneity . However, heterogeneity did not decrease (data not shown). Finally, combine and analyze of risk factors using a random effects model. As shown in (Table 2), axillary lymph node dissection $(\mathrm{OR}=3.73,95 \%$ CI 1.16 to $11.96, p=0.027)$, postoperative complications ( $\mathrm{OR}=2.64,95 \% \mathrm{CI} 1.10$ to $6.30, p=0.029)$,
Figure 7. Forest Plot of Radiotherapy

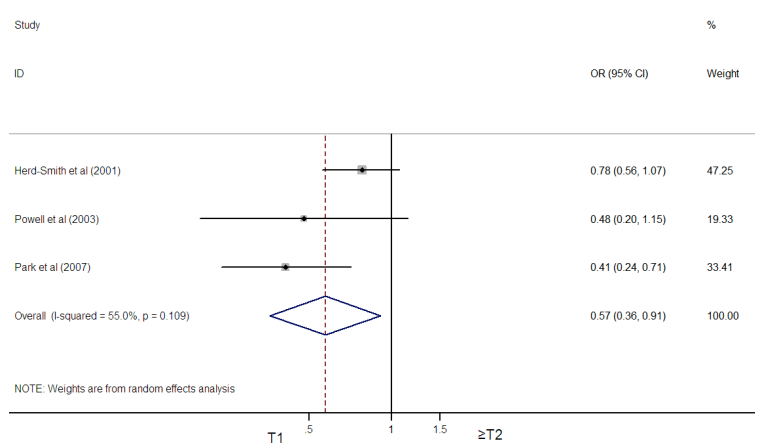

Figure 8. Forest Plot of Pathologic T Classification

hypertension ( $\mathrm{OR}=1.83,95 \% \mathrm{CI} 1.38$ to $2.42, p=0.000)$, body mass index $(\mathrm{OR}=1.80,95 \% \mathrm{CI} 1.30$ to 2.49 , $p=0.000)$, chemotherapy $(\mathrm{OR}=1.38,95 \% \mathrm{CI} 1.07$ to $1.79, p=0.015)$, radiotherapy $(\mathrm{OR}=1.35,95 \% \mathrm{CI} 1.10$ to $1.66, p=0.005)$. We found significant protective factors for lymphedema: pathologic $\mathrm{T}$ classification $(\mathrm{OR}=0.57$, $95 \%$ CI 0.36 to $0.91, p=0.019)$, stage $(\mathrm{OR}=0.60,95 \% \mathrm{CI}$ 0.39 to $0.93, p=0.023$ ). Draw forest plots with stata5.0 software respectively (Figure 2-9). 


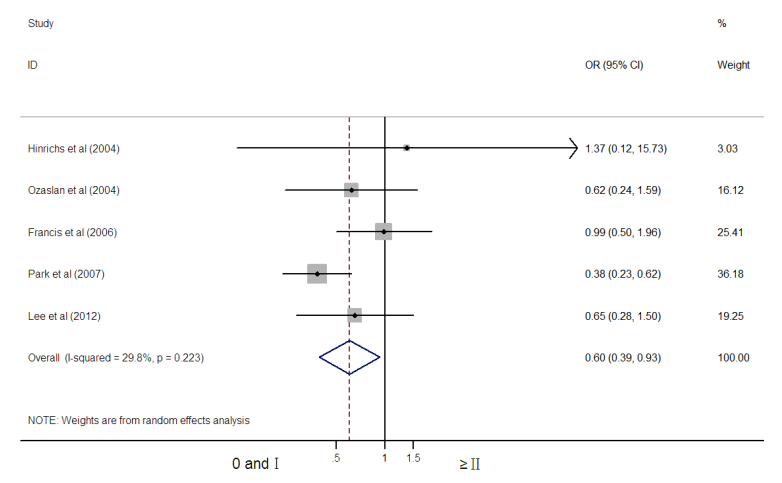

Figure 9. The Forest Plot of Stage

Publication bias and sensitivity analysis using Begg's funnel plot and Egger's test were to estimate the potential publication bias of the included literature.

\section{Discussion}

Breast cancer is a common cancer in Asian Pacific Region, with most of patients being treated by surgery and chemo-, radiotherapy. (Kochhar et al., 2013; Gang et al., 2013; Mohammadi et al., 2013; Boonlikit et al., 2013; Cabuk et al., 2014; Hu et al., 2014; Ozkan-Gurdal et al., 2014; El Sharkawi et al., 2014; Meiyanto et al., 2014; Avci et al., 2014; Fouladi et al., 2014; Alipour et al., 2014). We comprehensively reviewed risk factors for lymphedema among breast cancer survivors. The results showed : the risk of group with axillary lymph node dissection (ALND) was 2.72 times compared with group with no ALND. Most studies identified axillary dissection as a risk factor for lymphedema. For example: Paskett et al (Paskett et al., 2007) and Goffman et al (Goffman et al., 2004). Possible Causes: excessive extent of surgery destructed the lymphatic transport between the upper extremity and neck, breast tissue, especially the lymphatic vessel along the cephalic vein. Some studies (Schrenk et al., 2000; Baron et al., 2002) reported there was different risk of lymphedema between sentinel lymph node biopsy (SLND) compared with ALND, and had possibility of reducing the incidence of lymphedema. But this study had few articles which SLND compared with ALND, we can not analyze the incidence of lymphedema between SLND and ALND. Future research should focus on the effect on lymphedema about SLND and different incidences compared with ALND.

In this study, we get an important risk factor of BCRL: postoperative complications and pooled OR and 95\%CI $(\mathrm{OR}=2.64,95 \% \mathrm{CI} 1.10$ to 6.30$) . p=0.029<0.05 \mathrm{was}$ considered statistically significant. Postoperative complications mainly referred to infection in this study. McLaughlin et al (Mclaughin et al., 2008) and Hinrichs et al (Hinrichs et al., 2004) also got the same conclusion .But specific reasons were still unclear. Poss-bily, Infection caused by poor wound healing or improper care will further damage lymphatic and hinder the lymphatic reconstruction and establishment of collateral circulation.Thus it will aggravate or cause upper extremity lymphedema.

Kocak (Kocak et al., 2000) and Soran (Soran et al., 2006) think hypertension is risk factors of BCRL. But they did not provide enough evidence to make everyone recognized. Possible reasons: Local lymphatic drainage declined on patients with ALND and could cause upper extremity lymphedema.The study calculated the adjusted $\mathrm{OR}$ and $95 \% \mathrm{CI}(\mathrm{OR}=1.83,95 \% \mathrm{CI} 1.38$ to 2.42 , $p=0.000)$ by meta-analysis. So there was significance between hypertension and lymphedema. Breast cancer patients with hypertension increased risk of lymphedema compared with those who not.

Body mass index (BMI) is one of risk factors for lymphedema after breast cancer treatment (Ridner et al., 2011), we also get the same conclusion. Possibly people with larger BMI need greater blood circulation and lymphatic system to facilitate fluid flow. It is likely to cause the apacity of lymph and circulatory imbalanced. Mak et al (Mak et al., 2008) thought the obesity were susceptible to fat necrosis, poor wound healing and infection, thus leading to lymphedema.

Chemotherapy has been used clinically for many years as adjuvant treatment of breast cancer. But whether it can cause lymphedema, many studies have reported mixed results. Paskett (Paskett et al., 2007), Lee (Lee et al., 2012) and Haddad (Haddad et al.) et al thought chemotherapy can cause BCRL.But Tsai (Tsai et al., 2009) reported there was no relation betweeb BCRL and chemotherapy. Patients withchemotherapy were likely to receive invasive surgery and postoperative radiotherapy due to late stage of diseas.We combined $\mathrm{OR}$ values and 95\% CI among a lot of research: $(\mathrm{OR}=1.38,95 \% \mathrm{CI} 1.07$ to $1.79, p=0.015)$. So we conclude chemotherapy is one risk factor for BCRL.

Many studies suggest that radiotherapy is an independent risk factor of BCRL (Herd et al., 2011; Engel et al., 2003; Geller et al., 2003; Deo et al., 2004; Ozaslan et al., 2004; Clark et al., 2005; Hayes et al., 2005; Paskett et al., 2007; Hayes et al., 2008; Park et al., 2008; Meeske et al., 2009; Lee et al., 2012). The same conclusion as many studies had been reported. We draw forest plots with stata software: $\mathrm{OR}=1.35,95 \% \mathrm{CI} 1.10$ to 1.66 .Currently reasons radiotherapy-induced of BCRL is not very clear, the reasons were considered that radiotherapy can cause the venous occlusion within radiation field, lymphatic damage and oppress venous and lymphatic due to local muscle fibrosis.

Pathologic T classification and stage were significant protective factors for lymphedema. The lower stage, the lower incidence of lymphedema. On the other hand, the later the stage, the higher degree of malignancy of breast cancer, so the extent of surgery will expand. The risk for lymphedema will become high with it.

Many studies controversied about whether age is a risk factor for lymphedema. Some studies thought young breast cancer survivors were more easier to develop lymphedema (Armer et al., 2005). Young patients may havea higher degree of malignancy of breast cancer. But some persisted patients with old age ones would be easier to develop lymphedema (Kiel et al., 1996). Lymphaticvenous anastomosis will decrease with age older and Lymphatic drainage compensatory capacity also decrease (Clough et al., 2010). We combined many studies with age and did not find obvious correlation between age and lymphedema. In addition, we also combined No. of nodes dissected, No. of positive lymph nodes, Lymph node status 
and did not find the relation with lymphedema.

The results of Egger's test showed this study had better stability, publication bias was small, and the data obtained were reliable. So it can provide evidence and guidelines for the prevention and treatment of lymphedema in Clinical work. But limitations of the study: (Cheville et al., 2003) This study only retrieved PubMed, Ovid and other English database and had possibility of missing data, thus affecting research. (Hayes et al., 2012) Potential publication bias of Egger's test was inevitable and impacted the result finally.

In summary, we found that risk factors for BCRL from strong to weak as follows: axillary lymph node dissection, postoperative complications, hypertension, body mass index, chemotherapy, radiotherapy are risk factors for lymphedema after breast cancer treatment. Stage and Pathologic T classification are important protective factors. The results of some studies were inconsistent and different, for example: age, treatment on dominant side and endocrine therapy. Some factors (marital status, race, education level, employment status, smoking ) also get more and more attention in recent years. Although in recent years the incidence of BCRL declines, the treatment is still very difficult problem. Lack of effective cure for lymphedema, so preventing its occurrence is particularly important. But risk factors and pathogenesis for BCRL have not been fully elaborated, there need to be confirmed by further studies.

\section{Acknowledgements}

This work is Supported by Jiangsu Province's Key Medical Department in 2011 (No. 201112) and Jiangsu Province Health Department Research Project (No. z201305).

\section{References}

Alipour S, Hadji M, Hosseini L, et al (2014). Levels of serum 25-hydroxy-vitamin D in benign and malignant breast masses. Asian Pac J Cancer Prev, 15, 129-32.

Avci IA, Kumcagiz H, Altinel B, et al (2014). Turkish female academician self-esteem and health beliefs for breast cancer screening. Asian Pac J Cancer Prev, 15, 155-60.

Armer J, Fu MR (2005). Age differences in post-breast cancer lymphedema signs and symptoms. Cancer Nurs, 28, 2007; 208-9.

Baron RH, Fey JV, Raboy S, et al. (2002). Eighteen sensations after breast cancer surgery: a comparison of sentinel lymph node biopsy and axillary lymph node dissection. Oncol Nurs Forumv, 29, 651-9.

Boonlikit S (2013). Comparison of mammography in combination with breast ultrasonography versus mammography alone for breast cancer screening in asymptomatic women. Asian Pac J Cancer Prev, 14, 7731-6.

Cabuk D, Basaran G, Teomete M, et al (2014). Clinical outcome of Turkish metastatic breast cancer patients with currently available treatment modalities--single center experience. Asian Pac J Cancer Prev, 15, 117-22.

Cheville AL, McGarvey CL, Petrek JA, et al (2003). The grading of lymphedema in oncology clinical trials. Semin Radiat Oncol, 13, 214-25.

Clark B, Sitzia J, Harlow W. (2005). Incidence and risk of arm oedema following treatment for breast cancer: a three-year follow-up study. $Q J M, 98,343-8$.

Clough-Gorr KM, Ganz PA, Silliman RA (2010). Older breast cancer survivors: factors associated with self-reported symptoms of persistent lymphedema over 7 years of followup. Breast J, 16, 147-55.

CardA, CrosbyMA, Liu J, et al (2012). Reduced incidence of breast cancer-related lymphedema following mastectomy and breast reconstruction versus mastectomy alone. Plast Reconstr Surg, 130, 1169-78.

Deo SV, Ray S, Rath GK, et al (2004). Prevalence and risk factors for development of lymphedema following breast cancer treatment. Indian J Cancer, 41, 8-12.

Egger M, Schneider M, Davey Smith G (1998). Spurious precision? Meta-analysis of observational studies. BMJ, 316, 140-4.

Egger M, Davey Smith G, Schneider M, et al (1997). Bias in meta-analysis detected by a simple, graphical test. $B M J$, 315, 629-34.

El Sharkawi FZ, El Shemy HA, Khaled HM (2014). Possible anticancer activity of rosuvastatine, doxazosin, repaglinide and oxcarbazepin. Asian Pac J Cancer Prev, 15, 199-203.

Engel J, Kerr J, Schlesinger-Raab A, et al (2003). Axilla surgery severely affects quality of life: results of a 5-year prospective study in breast cancer patients. Breast Cancer Res Treat, 79, 47-57.

Fouladi N, Ali-Mohammadi H, Pourfarzi F, et al (2014). Exploratory study of factors affecting continuity of cancer care: Iranian Women's perceptions. Asian Pac J Cancer Prev, 15, 133-7.

Francis WP, Abghari P, Du W, et al (2006). Improving surgical outcomes: standardizing the reporting of incidence and severity of acute lymphedema after sentinel lymph node biopsy and axillary lymph node dissection. American $J$ Surgery, 192, 636-9.

Gang M, Kim JI, Oh KO, et al (2013). Factors associated with mammography adherence among married Chinese women in Yanbian, China. Asian Pac J Cancer Prev, 14, 7207-13.

Geller BM, Vacek PM, O'Brien P, et al (2003). Factors associated with arm swelling after breast cancer surgery $(\mathrm{J})$. $J$ Womens Health (Larchmt), 12, 921-30.

Graham P, Jagavkar R, Browne L, et al (2006). Supraclavicular radiotherapy must be limited laterally by the coracoid to avoid significant adjuvant breast nodal radiotherapy lymphoedema risk. Australas Radiol, 50, 578-82.

Goffman TE, Laronga C, Wilson L, et al (2004). Lymphedema of the arm and breast in irradiated breast cancer patients: risks in an era of dramatically changing axillary surgery. Breast $J, \mathbf{1 0}, 405-11$.

Hayes SC, Johansson K, Stout NL, et al (2012). Upper-body morbidity after breast cancer: incidence and evidence for evaluation, prevention, and management within a prospective surveillance model of care. Cancer, 118, 2237-49.

Heiney SP, McWayne J, Cunningham JE, et al (2007). Quality of life and lymphedema following breast cancer. Lymphology, 40, 177-84.

Herd-Smith A, Russo A, Muraca MG, et al (2001). Prognostic factors for lymphedema after primary treatment of breast carcinoma. Cancer, 92, 1783-7.

Hinrichs CS, Watroba NL, Rezaishiraz H, et al (2004). Lymphedema secondary to postmastectomy radiation:incidence and risk factors. Ann Surg Oncol, 11, 573-80.

Hayes S, Cornish B, Newman B (2005). Comparison of methods to diagnose lymphoedema among breast cancer survivors: 6-month follow-up. Breast Cancer Res Treat, 89, 221-6.

Hayes SC, Janda M, Cornish B, et al (2008). Lymphedema after breast cancer: incidence, risk factors, and effect on upper 
body function. J Clin Oncol, 26, 3536-42.

Haddad P, Farzin M, Amouzegar-Hashemi F, et al (2010). A multicentre cross-sectional study of arm lymphedema four or more years after breast cancer treatment in Iranian patients. Breast Cancer, 17, 281-5.

Hu Q, Luo Z, Xu T, et al (2014). FOXA1: a promising prognostic marker in breast cancer. Asian Pac J Cancer Prev, 15, 11-6.

Kiel KD, Rademacker AW (1996). Early-stage breast cancer: arm edema after wide excision and breast irradiation. Radiology, 198, 279-83.

Kocak Z, Overgaard J (2000). Risk factors of arm lymphedema in breast cancer patients. Acta Oncol, 39, 389-92.

Kochhar AK, Jindal U, Singh K (2013). Spectrum of cytological findings in fine needle aspiration cytology of breast lumps with histopathology correlation: experience in a tertiary care rural hospital in India. Asian Pac J Cancer Prev, 14, 7257-60.

Lee SH, Min YS, Park HY, et al (2012). Health-related quality of life in breast cancer patients with lymphedema who survived more than one year after surgery. J Breast Cancer, 15, 449-53.

McCredie MR, Dite GS, Porter L, et al (2001). Prevalence of self-reported arm morbidity following treatment for breast cancer in the Australian Breast Cancer Family Study. Breast, 10, 515-22.

McLaughlin SA, Wright MJ, Morris KT, et al (2008). Prevalence of lymphedema in women with breast cancer 5 years after sentinel lymph node biopsy or axillary dissection: objective measurements. J Clin Oncol, 26, 5213-9.

Mak SS, Yeo W, Lee YM, et al (2008). Predictors of lymphedema in patients with breast cancer undergoing axillary lymph node dissection in Hong Kong. Nurs Res, 57, 416-25.

Meeske KA, Sullivan-Halley J, Smith AW, et al (2009). Risk factors for arm lymphedema following breast cancer diagnosis in Black women and White women. Breast Cancer Res Treat, 113 , 383-91.

Meiyanto E, Putri DD, Susidarti RA, et al (2014). Curcumin and its analogues (PGV-0 and PGV-1) enhance sensitivity of resistant MCF-7 cells to doxorubicin through inhibition of HER2 and NF-kB activation. Asian Pac J Cancer Prev, 15, 179-84.

Mohammadi S, Sulaiman S, Koon PB, et al (2013). Association of nutritional status with quality of life in breast cancer survivors. Asian Pac J Cancer Prev, 14, 7749-55.

Ozaslan C, Kuru B. Lymphedema after treatment of breast cance r. American Journal of Surgery, 2004, 187, 69-72.

Ozkan-Gurdal S, Cabioglu N, Ozcinar B, et al (2014). Factors predicting microinvasion in ductal carcinoma in situ. Asian Pac J Cancer Prev. 15, 55-60.

Pyszel A, Malyszczak K, Pyszel K, et al (2006). Disability, psychological distress and quality of life in breast cancer survivors with arm lymphedema. Lymphology, 39, 185-92.

Powell SN, Taghian AG, Kachnic LA, et al (2003). Risk of lymphedema after regional nodal irradiation with breast conservation therapy. Int J Radiat Oncol Biol Phys, 55, 1209-15.

Paskett ED, Naughton MJ, McCoy TP, et al (2007). The epidemiology of arm and hand swelling in premenopausal breast cancer survivors. Cancer Epidemiol Biomarkers Prev, 16, 775-82.

Park JH, Lee WH, Chung HS (2006). Incidence and risk factors of breast cancer lymphoedema. J Clin Nurs, 2008, 17, 1450-9.

Ridner SH. Pretreatment lymphedema education and identified educational resources in breast cancer patients. Patient Educ Couns, 61, 72-9.

Ridner SH, Dietrich MS, Stewart BR, et al (2011). Body mass index and breast cancer treatment-related lymphedema.
Support Care Cancer, 19, 853-7.

Sakorafas GH, Peros G, Cataliotti L, et al (2010). Lymphedema following axillary lymph node dissection for breast cancer. Surg Oncol, 15, 153-65.

Sagen A, Karesen R, Risberg MA (2009). Physical activity for the affected limb and arm lymphedema after breast cancer surgery. A prospective, randomized controlled trial with two years follow-up. Acta Oncol, 48, 1102-10.

Shih YC, Xu Y, Cormier JN, et al (2009). Incidence, treatment costs, and complications of lymphedema after breast cancer among women of working age: a 2-year follow-up study. $J$ Clin Oncol, 27, 2007-14.

Schrenk P, Rieger R, Shamiyeh A, et al (2000). Morbidity following sentinel lymph node biopsy versus axillary lymph node dissection for patients with breast carcinoma. Cancer, 88, 608-14.

Soran A, D'Angelo G, Begovic M, et al (2006). Breast cancerrelated lymphedema--what are the significant predictors and how they affect the severity of lymphedema?. Breast $J, 12,536-43$.

Tsai RJ, Dennis LK, Lynch CF, et al (2009). The risk of developing arm lymphedema among breast cancer survivors: a meta-analysis of treatment factors. Ann Surg Oncol, 16, 1959-72. 